\title{
Two Grams BID Is an Oral Dosage of Vitamin C to Reduce the Risk of Recurrence of Superficial Bladder Carcinoma
}

\author{
Edward Folk ${ }^{1}$ Tracy M. Downs ${ }^{2}$, Alfred Roc Ordman ${ }^{3}$ \\ ${ }^{1}$ Beloit College Biochemistry Program, Beloit, USA \\ ${ }^{2}$ Department of Urology, UW-Madison School of Medicine and Public Health, Madison, USA \\ ${ }^{3}$ Beloit College, Beloit, USA \\ Email: ordman@beloit.edu
}

Received 1 January 2015; accepted 4 January 2015; published 9 January 2015

Copyright (C) 2015 by authors and Scientific Research Publishing Inc.

This work is licensed under the Creative Commons Attribution International License (CC BY). http://creativecommons.org/licenses/by/4.0/

c) (i) Open Access

\section{Abstract}

Background: Continuous exposure to millimolar (mM) Vitamin C (AA) in vitro kills cancer cells. For superficial bladder carcinoma (SBC), standard chemotherapy is instillation of Bacillus Calmette-Guerin. The recurrence rate with this therapy is $91 \%$. But high dosage vitamins including AA reduced the recurrence to $41 \%$. Aim: To determine the oral dosage of AA that causes the highest concentration of AA [AA] in the bladder. Method: We conducted a clinical trial of 14 people who took various dosages of AA, and analyzed the [AA] in their urine. Results: AA above $2 \mathrm{~g}$ twice a day was not absorbed. But that intake produced a bladder [AA] above $1 \mathrm{mM}$ in all participants. Conclusion: Taking $2 \mathrm{~g}$ of AA BID will increase [AA] in the bladder to a level likely to kill cancer cells that cause SBC. Taking that dosage 2 consecutive days a week is likely to reduce the recurrence rate of SBC substantially.

\section{Keywords}

Cancer, Vitamin C, LUTS, Superficial Bladder Carcinoma

\section{Introduction}

Linus Pauling proposed that taking megadoses of Vitamin $\mathrm{C}$ (ascorbic acid, AA) has many benefits. Among his results [1] are that AA significantly prolonged the fraction of survivors at times after date of onset of terminal stage (untreatable) cancer patients. Many patients had received an oral dose of $10 \mathrm{~g}$ daily.

AA enhances survival of cancer patients in vivo when properly administered IV (intravenously) rather than

How to cite this paper: Folk, E., Downs, T.M. and Ordman, A.R. (2015) Two Grams BID Is an Oral Dosage of Vitamin C to Reduce the Risk of Recurrence of Superficial Bladder Carcinoma. Journal of Cancer Therapy, 6, 169-176. 
orally [2]. "Observational reports described ascorbate, given in pharmacologic doses of $10 \mathrm{~g}$ daily, as effective in treating some cancers and in improving patient well-being” [2] (Figure 1 [3] [4]). Ongoing research continues to improve the effectiveness of AA in killing cancer cells [5]. Subsequently, the same dose had no effect on patient well-being and survival in two double-blind placebo-controlled trials, and AA was discarded as a treatment modality [6] [7]. Recent clinical evidence, however, indicates that the role of AA in cancer treatment should be examined anew [8]. The originally reported observational studies used IV and oral AA, but the subsequent doubleblind placebo-controlled studies used only oral AA. It was not recognized that the route of AA administration might produce large differences in plasma concentrations. Recent pharmacokinetics studies in men and women show that $10 \mathrm{~g}$ of AA given IV are expected to produce plasma concentrations of nearly $6 \mathrm{mM}$, which are 75fold higher than those concentrations from the same oral dose [8] [9]. The maximum serum concentration achievable by oral AA is $80 \mu \mathrm{M}$. The potential of IV AA to treat cancer is being explored [10], in at least 8 clinical trials currently [11].

It is estimated that 73,510 people will be diagnosed with and 14,880 will die of cancer of the urinary bladder in 2012 [12]. Developed in 1976 by Morales [13], normal chemotherapy for superficial bladder carcinoma (SBC) is instillation with intravesical Bacillus Calmette-Guerin (BCG). However, such cancers "commonly exhibit a very aggressive behavior and carry a grave prognosis", and the 5-year recurrence rate is 91\%. Lamm [14] developed a megavitamin protocol that reduces recurrence to just $41 \%$. However, many bladder oncologists do not use this modification.

When Lamm was publishing his megavitamin protocol, he was unaware of Ordman's discovery [15] that AA must be taken twice a day (BID) to maintain elevated levels in the serum, a result we showed next for calcium [16] and eventually assumed for all water-soluble nutrients. In 1994, we published in AGE [15] that when people consume AA orally, AA intake above $500 \mathrm{mg}$ is excreted in the urine over $12 \mathrm{hr}$, and that $500 \mathrm{mg}$ must be consumed twice a day to guarantee continuous excretion of excess in the urine (Figure 2). Levine [9] showed the relationship between oral AA dosage and serum levels, confirming Ordman's conclusion that $500 \mathrm{mg}$ AA BID produces the highest statistically significant serum concentration of Vitamin C [AA] in people. That [AA] is about $80 \mu \mathrm{M}$, while the RDA (recommended daily allowance) produces only about $25 \mu \mathrm{M}$. The RDA is established by the US Food and Nutrition Board to reduce the risk of deficiency likely to cause short-term illness in

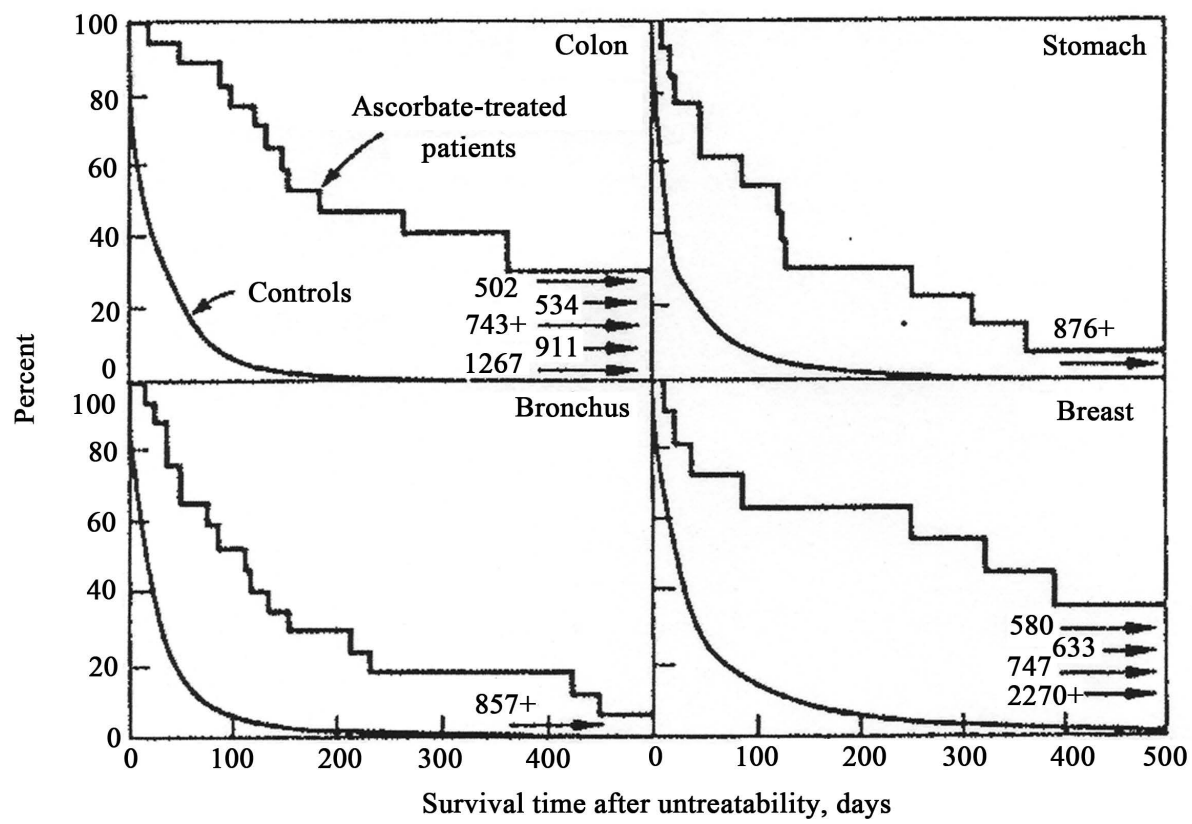

Figure 1. Fraction of survivors at times after date of onset of terminal stage (untreatability) of AA-treated patients with primary cancer of colon, stomach, bronchus, or breast, compared with that for matched controls (10 per ascorbate-treated patient). Many patients were given 10 g daily orally, but a variety of other AA treatments were used. Copyright 1976 National Academy of Sciences, USA [4]. 


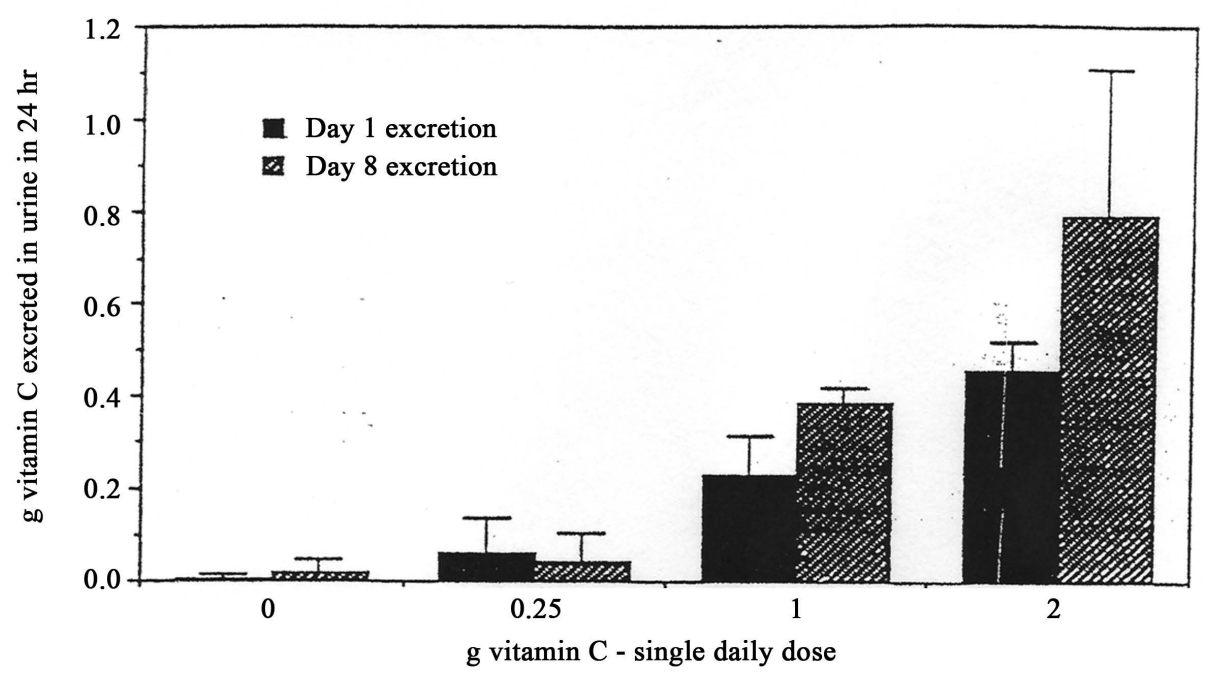

Figure 2. Relationship of dose of AA to total urinary excretion. Individuals took AA daily at 8 am for 8 days. All urine was collected during the first and last day. Each bar represents the mean for 5 individuals [14].

the US population. Recent studies indicate 40\% of Americans take AA supplements [17].

In his megavitamin treatment, Lamm also did not note that the $2 \mathrm{~g}$ of AA was probably the active ingredient. Chen et al. [2] demonstrated in tissue culture that 5 cancer cell lines had $\mathrm{EC}_{50}$ values of $<4 \mathrm{mM}$ but normal cells were unaffected by $20 \mathrm{mM}$ (Figure 3). They proposed the mechanism by which AA kills cancer cells without harming normal cells. Extracellular but not intracellular AA mediated cell death, which occurred by apoptosis and pyknosis/necrosis. Cancer cells catalyzed the generation of hydrogen peroxide from AA, while normal cells did not. Although AA addition to medium generated $\mathrm{H}_{2} \mathrm{O}_{2}$, AA, in addition to blood, generated no detectable $\mathrm{H}_{2} \mathrm{O}_{2}$ and only trace detectable AA radical. However, it is still accepted among many oncologists, e.g. at the Mayo Clinic web site, that high dose IV AA is ineffective [18]. Yet AA is used intravenously with cancer patients and increases efficacy in conjunction with a variety of chemotherapies, as reviewed by Levine at NIH [19]. A survey indicated more than 8800 patients were treated with IV AA in 2008 [20].

Current SBC treatment with BCG does not include the megavitamin protocol. In reviewing Lamm's result, Ordman noticed that Lamm's megavitamin included $2 \mathrm{~g}$ AA daily. In contrast to intravenous AA required to elevate serum concentrations to treat most cancers, oral AA is absorbed into the serum, and removed by the kidneys through the bladder in urine. Since AA kills cancer cells without harming healthy ones, we realized that an oral dose of AA could be found that would provide the maximum continuous [AA] in the bladder, and that this might significantly and safely reduce the recurrence of SBC.

Normal daily urine output is estimated 0.5 to 2 liters. Given that doses above $500 \mathrm{mg}$ AA BID are excreted, we hypothesized that taking $2 \mathrm{~g}$ AA BID would produce a urine [AA] of approximately $14 \mathrm{mM}$, a level demonstrated to kill cancer but not harm normal human cells.

The objective of this study is to confirm our hypothesis that $2 \mathrm{~g}$ AA BID will produce a [AA] in the urine high enough to be able to kill cancer cells on the inner lining of the bladder.

\section{Materials and Methods}

\subsection{Study Population}

Beloit College Institutional Review Board approval was received before experimentation began. Fourteen students age 18 - 22 weighing 47 to $141 \mathrm{~kg}$ volunteered to participate in the trial.

\subsection{Regimen and Compliance}

The subjects took $2 \mathrm{~g}$ of AA (four Spring Green $500 \mathrm{mg}$ tablets) at 9 am and again at 9 pm. Participants wrote down when doses were taken, and confirmed this to those collecting their urine. 


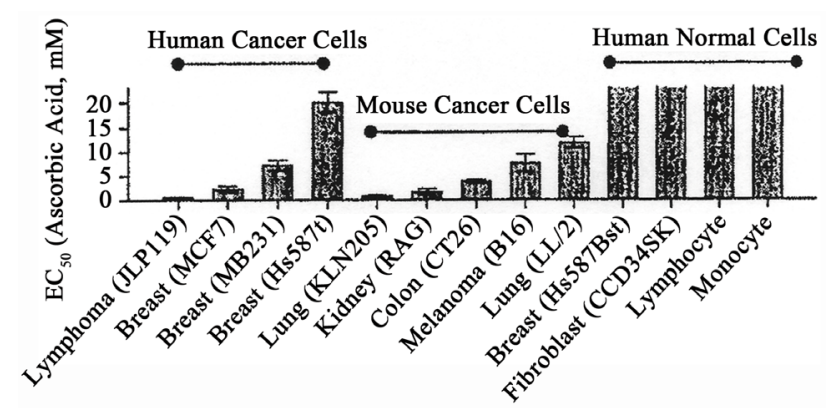

(a)

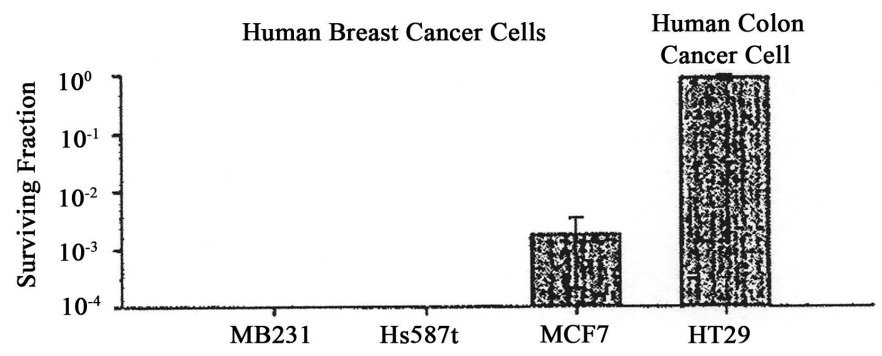

(b)

Figure 3. Effects of pharmacologic [AA] on cancer and normal cells. (a) EC $\mathrm{C}_{50}$ values of ascorbate in human and mouse cancer cells and normal humans cells. All cells were treated with

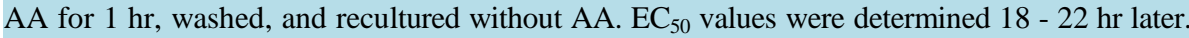
(b) Colony formation of cancer cells in soft agar after $1 \mathrm{hr}$ treatment with $5 \mathrm{mM}$ AA. Surviving fraction, expressed in log scale, indicates number of treated colonies compared with matched untreated control cells. Copyright 2005 National Academy of Sciences, USA [2].

\subsection{Sampling}

Urine samples were collected 5 to 12 hours after the second dose was consumed.

\subsection{Study Endpoints and Laboratory Methods}

Oxalic acid was immediately added to stabilize the AA. The samples were put on ice until they were assayed with dichlorophenol-indophenol (DCIP) [21] in the next few hours. The [AA] of the samples was determined with an Ocean Optics spectrophotometer at $520 \mathrm{~nm}$. This procedure was repeated twice with the same subjects.

\section{Results}

The results of the exploratory trial were used to determine a 2 g AA BID dosage (Table 1) and BID dosing (Table 2) that would produce the highest [AA] in the bladder. The pilot trial showed that dosages above $500 \mathrm{mg}$ BID were necessary to guarantee continuous excretion from the bladder, and that dosages above $2 \mathrm{~g}$ BID were not absorbed from the intestine. After the peak concentration was achieved, it was maintained continuously during a week that the dosage was taken. Neither larger nor more frequent doses raised urinary [AA] any further.

The participants for this trial were from 18 to 22-year-old non-smokers and stated they were of good health, with most being male (Table 3). Table 4 illustrates the results of the trial. The difference [AA] within individuals in the two trials likely results from different volumes of urine production. Three of the 14 reported minor indigestion.

Comparison of the maximum AA achieved vs. the level required to kill cancer cells:

Table 5 shows that bladder [AA] achieved by 2 g AA BID is likely to kill SBC cells in vivo. The AA levels ranged from 2.7 to $27.8 \mathrm{mM}$ AA, which is much greater than the $2 \mathrm{mM}$ level required to kill cancer cells in vitro [2]. 
Table 1. Effect of BID dose on the urinary [AA].

\begin{tabular}{cc}
\hline AA Dosage Taken Twice a Day & Urinary [AA] \\
\hline $1 \mathrm{~g}$ & $1 \mathrm{mM}$ \\
$2 \mathrm{~g}$ & $6 \mathrm{mM}$ \\
$3 \mathrm{~g}$ & $7 \mathrm{mM}$ \\
$6 \mathrm{~g}$ & $6 \mathrm{mM}$ \\
\hline
\end{tabular}

Table 2. Effect of frequency of dosing on urinary [AA].

\begin{tabular}{ccc}
\hline Dosage & Frequency & Urinary [AA], mM \\
\hline $1 \mathrm{~g}$ & Hourly & $6 \mathrm{mM}$ \\
$1 \mathrm{~g}$ & Every $12 \mathrm{hr}$ & $1 \mathrm{mM}$ \\
$2 \mathrm{~g}$ & Every $12 \mathrm{hr}$ & $6 \mathrm{mM}$ \\
\hline
\end{tabular}

Table 3. Characteristics of participants.

\begin{tabular}{cccc}
\hline Person & Gender & Weight $(\mathrm{kg})$ & Exercise (min/week) \\
\hline 1 & M & 102 & 900 \\
2 & M & 93 & 840 \\
3 & F & 79 & 0 \\
4 & M & 77 & 1080 \\
5 & M & 93 & 780 \\
6 & F & 47 & 0 \\
7 & F & 53 & 225 \\
8 & M & 141 & n.d. \\
9 & M & 90 & 1200 \\
10 & F & 66 & 100 \\
11 & M & 65 & 240 \\
12 & M & 69 & 0 \\
13 & M & 76 & 300 \\
14 & M & 68 & 240 \\
\hline
\end{tabular}

Table 4. Effect of BID dose on the urinary [AA]—Variation among participants.

\begin{tabular}{cccc}
\hline Person & Gender & [AA], mM & [AA], mM \\
\hline 1 & M & 1 st trial & \\
2 & M & 2.66 & \\
3 & F & 2.68 & \\
4 & M & 3.85 & 6.40 \\
5 & M & 4.09 & \\
6 & F & 5.64 & 9.53 \\
7 & F & 6.37 & 8.32 \\
8 & M & 6.68 & 10.72 \\
9 & M & 7.40 & 10.62 \\
10 & F & 7.41 & 23.20 \\
11 & M & 8.46 & 11.40 \\
12 & M & 8.57 & 20.21 \\
13 & M & 9.56 & 27.80 \\
14 & M & 11.90 & \\
& Range Females = 3.85 to $10.62 \mathrm{mM}$ & \\
\end{tabular}


Table 5. Comparison of the maximum [AA] achieved vs. the level required to kill cancer cells.

\begin{tabular}{cccccc}
\hline Condition & $\begin{array}{c}\text { [AA], mM } \\
\text { in medium }\end{array}$ & Dosage & Duration & Result & Ref. \\
\hline SBC in the bladder & n.d. & 2 g once daily & $12 \mathrm{hr}$ & Recurrence reduced from 91\% to 41\% & {$[14]$} \\
SBC in the bladder & 2.7 to 27.8 & $2 \mathrm{~g} \mathrm{BID}$ & Continuous & Clinical trial planned & here \\
Cancer cells in tissue culture & 2 & In vitro $2 \mathrm{mM}$ continuous & $1 \mathrm{hr}$ & Nearly 100\% & {$[2]$} \\
Normal cells in tissue culture & 20 & In vitro $20 \mathrm{mM}$ continuous & $1 \mathrm{hr}$ & $100 \%$ survival & {$[2]$} \\
\hline
\end{tabular}

\section{Discussion}

Taking 2 g AA raises the concentration of AA filtered by the kidneys to a maximum of approximately 6 mM. Our previous work [15] demonstrated that when AA is taken orally, the concentration in urine rises over $4 \mathrm{hr}$, remains elevated for the next $12 \mathrm{hr}$, and then falls rapidly, unless another dose of AA has been consumed. A single daily dose of $2 \mathrm{~g}$ will elevate the bladder concentration for at most $12 \mathrm{hr}$. Our results show that a $2 \mathrm{~g}$ dose is the most that will be absorbed. While Figure 3 shows that exposure of cancer cells to AA of 1 hr is sufficient to kill them, providing a longer exposure in vivo seems prudent. Higher and more frequent doses shown in Table 1 and Table 2 did not raise urinary AA further, so excess AA must not be absorbed into the serum, and be disposed through the intestines. To maintain the $6 \mathrm{mM}$ [AA] continuously, taking the dosage every $12 \mathrm{hr}$ is necessary and sufficient.

AA is approved by the US Food and Drug Administration as a GRAS (generally recognized as safe) substance. Two-time Nobel Prize winner Linus Pauling took $16 \mathrm{~g}$ daily for years without side effects. In the latest statement issued by the Food and Nutrition Board for the USDA, the chair of the panel on antioxidants, Maret Traber, set the upper limit for AA at $2 \mathrm{~g}$ daily [22]. Using this level chronically may cause diarrhea in a few individuals. A review states clearly that high dosages of AA cause no apparent harm [19]. One hazardous side effect of AA is that wound healing takes longer, so it should not be consumed within a week of bleeding. Another side effect of high doses of supplemental AA that is documented in peer-reviewed literature was reported in 2011, when it was shown that taking AA supplements regularly causes LUTS in $21 \%$ of older men [23]. LUTS is lower urinary tract symptoms, specifically more difficulty with and frequency of urinating, similar to prostate hyperplasia. It remains unclear whether AA contributes to kidney stones. AA can be biochemically metabolized to oxalic acid, and oxalic acid forms kidney stones. For this reason many physicians believe that consuming AA increases the risk of kidney stones. However, a reduction in the risk for kidney stones was observed in those who take AA supplements [24]. A 2013 study by Thomas et al. [25] reported a 0.15\% increased risk in a Swedish population that takes single doses of $1 \mathrm{~g}$ or more through supplements. Other documented effects of AA are beneficial. These include a minor reduction in blood pressure [26], a reduction in cortisol levels [27], and a reduction in the risk of stroke damage [28]-[30].

In order to reduce the chance of causing LUTS, and considering that cancer often develops tolerance for many forms of chemotherapy, the proposal to conduct a clinical trial on those with SBC will include $2 \mathrm{~g}$ AA BID two consecutive days per week. We are assuming that AA will be processed by the kidneys of SBC patients as it is by our healthy volunteers. Our pre-trial involved participants taking $2 \mathrm{~g}$ of Vitamin $\mathrm{C}$ twice a day (4 g daily) to achieve a maximal concentration of AA in the bladder. Previously, it was thought that there was no benefit in taking more than $2 \mathrm{~g}$ of Vitamin C per day, but our research indicates that taking a higher dose, $4 \mathrm{~g}$ per day, will increase the concentration of AA in the bladder. We predict that the increased amount of AA in the bladder will help to prevent or treat SBC by killing any new cancer cells as soon as they develop in the bladder. This method may provide a cure for SBC.

\section{Conclusion}

Research about urinary excretion of AA indicates that the AA level in the bladder can be elevated simply by oral consumption. The maximum [AA] ranged from 2.7 to $27.8 \mathrm{mM}$, by consuming $2 \mathrm{~g}$ AA BID. For people with SBC, this method provides a level of AA in the bladder that can kill cancer cells, not harm normal tissue, and is likely to significantly reduce the rate of recurrence from $91 \%$ to no more than $41 \%$, and potentially much less. 


\section{Acknowledgements}

The authors thank Kevin T. Palmer, Joseph L. Poshepny, Alison Deng, R. Madeleine Hallberg, Ayca Kaplan, Ozgun Kilic, Donnia A. Robins, and Komari C. Walls of Beloit College for assistance in running and analyzing results of the trial, and the participants in the trial. This project was supported by Beloit College.

\section{References}

[1] Cameron, E. and Pauling, L. (1978) Supplemental Ascorbate in the Supportive Treatment of Cancer: Reevaluation of Prolongation of Survival Times in Terminal Human Cancer. Proceedings of the National Academy of Sciences of the United States of America, 75, 4538-4542. http://dx.doi.org/10.1073/pnas.75.9.4538

[2] Chen, Q., Levine, M., Buettner, G.R., et al. (2005) Pharmacologic Ascorbic Acid Concentrations Selectively Kill Cancer Cells: Action as a Pro-Drug to Deliver Hydrogen Peroxide to Tissues. Proceedings of the National Academy of Sciences of the United States of America, 102, 13604-13609. http://dx.doi.org/10.1073/pnas.0506390102

[3] Cameron, E. and Campbell, A. (1974) The Orthomolecular Treatment of Cancer. II. Clinical Trial of High-Dose Ascorbic Acid Supplements in Advanced Human Cancer. Chemico-Biological Interactions, 9, 285-315. http://dx.doi.org/10.1016/0009-2797(74)90019-2

[4] Cameron, E. and Pauling, L. (1976) Supplemental Ascorbate in the Supportive Treatment of Cancer: Prolongation of Survival Times in Terminal Human Cancer. Proceedings of the National Academy of Sciences of the United States of America, 73, 3685-3689. http://dx.doi.org/10.1073/pnas.73.10.3685

[5] Olney, K.E., et al. (2013) Inhibitors of Hydroperoxide Metabolism Enhance Ascorbate-Induced Cytotoxicity. Free Radical Research, 47, 154-163. http://dx.doi.org/10.3109/10715762.2012.755263

[6] Creagan, E.T., et al. (1979) Failure of High-Dose Vitamin C (Ascorbic Acid) Therapy to Benefit Patients with Advanced Cancer: A Controlled Trial. The New England Journal of Medicine, 301, 687-690. http://dx.doi.org/10.1056/NEJM197909273011303

[7] Moertel, C.G., et al. (1985) High-Dose Vitamin C versus Placebo in the Treatment of Patients with Advanced Cancer That Have Had No Prior Chemotherapy. The New England Journal of Medicine, 312, 137-141. http://dx.doi.org/10.1056/NEJM198501173120301

[8] Padayatty, S.J., et al. (2004) Vitamin C: Intravenous Use by Complementary and Alternative Medicine Practitioners and Adverse Effects. Annals of Internal Medicine, 140, 533-537. http://dx.doi.org/10.7326/0003-4819-140-7-200404060-00010

[9] Levine, M., et al. (1996) Vitamin C Pharmacokinetics in Healthy Volunteers: Evidence for a Recommended Dietary Allowance. Proceedings of the National Academy of Sciences of the United States of America, 93, 3704-3709. http://dx.doi.org/10.1073/pnas.93.8.3704

[10] Buetter, G.R., et al. (2011) Comment on "Pharmacologic Ascorbate Synergizes with Gemcitabine in Pre-Clinical Models of Pancreatic Cancer” i.e. All We Are Saying Is, Give C a Chance. Free Radical Biology and Medicine, 50, 17261727. http://dx.doi.org/10.1016/j.freeradbiomed.2011.03.030

[11] Clinical Trials (2013) www.clinicaltrials.gov

[12] National Cancer Institute (2012) Cancer Statistics. http://seer.cancer.gov/statfacts/html/urinb.html

[13] Morales, A. (1980) Treatment of Carcinoma in Situ of the Bladder with BCG. Cancer Immunology, Immunotherapy, 9, 69-72. http://dx.doi.org/10.1007/BF00199531

[14] Lamm, D.L., Riggs, D.R., Shriver, J.S., van Gilder, P.F., Rach, J.F. and De Haven, J.I. (1994) Megadose Vitamins in Bladder Cancer: A Double-Blind Clinical Trial. Journal of Urology, 151, 21-26.

[15] King, G., Beins, M., Larkin, J., Summers, B. and Ordman, A.B. (1994) Rate of Excretion of Vitamin C in Human Urine. AGE, 17, 87-92. http://dx.doi.org/10.1007/BF02435011

[16] Cone, A., Danner, T. and Ordman, A.B. (1996) Urinary Excretion of Calcium in Students and Mature Women Taking Supplements. AGE, 19, 164.

[17] Schleicher, R.L., Carroll, M.D., Ford, E.S. and Lacher, D.A. (2009) Serum Vitamin C and the Prevalence of Vitamin C Deficiency in the United States: 2003-2004 National Health and Nutrition Examination Survey (NHANES). American Journal of Clinical Nutrition, 90, 1252-1263. http://dx.doi.org/10.3945/ajcn.2008.27016

[18] Moynihan, T. (2012) High-Dose Vitamin C: Can It Kill Cancer Cells? Mayo Clinic Health Information. http://www.mayoclinic.com/health/alternative-cancer-treatment/AN01572

[19] Levine, M., Padayatty, S.J. and Espey, M.G. (2011) Vitamin C: A Concentration-Function Approach Yields Pharmacology and Therapeutic Discoveries. Advances in Nutrition, 2, 78-88. http://dx.doi.org/10.3945/an.110.000109

[20] Evers, E. (2012) Treat Cancer with IV Vitamin C-Recent Clinical Success. Natural News. 
http://www.naturalnews.com/034663_IV_vitamin_c_cancer_treatment.html

[21] Omaye, S.T., Turnbull, J.D. and Sauberlich, H.E. (1979) Selected Methods for the Determination of Ascorbic Acid in Animal Cells. Methods in Enzymology, 62, 3-11. http://dx.doi.org/10.1016/0076-6879(79)62181-X

[22] Institute of Medicine (2000) Panel on Dietary Antioxidants and Related Compounds, Dietary Reference Intakes for Vitamin C, Vitamin E, Selenium, and Carotenoids. National Academies Press, Washington DC.

[23] Maserejian, N.N., Giovannucci, E.L., McVary, K.T. and McKinlay, J.B. (2011) Dietary, but Not Supplemental, Intakes of Carotenoids and Vitamin C Are Associated with Decreased Odds of Lower Urinary Tract Symptoms in Men. Journal of Nutrition, 141, 267-273. http://dx.doi.org/10.3945/jn.110.132514

[24] Naidu, K.A. (2003) Vitamin C in Human Health and Disease Is Still a Mystery? An Overview. Journal of Nutrition, 2, 7-23. http://dx.doi.org/10.1186/1475-2891-2-7

[25] Thomas, L.D.K., Elinder, C.-G., Tiselius, H.-G., Wolk, A. and Akesson, A. (2013) Ascorbic Acid Supplements and Kidney Stone Incidence among Men: A Prospective Study. JAMA Internal Medicine, 173, 1-2.

[26] Newberry, S.J. (2012) What Is the Evidence That Vitamin C Supplements Lower Blood Pressure? American Journal of Clinical Nutrition, 95, 997-998. http://dx.doi.org/10.3945/ajcn.112.037663

[27] Staff (2012) Vitamin C: Stress Buster. Psychology Today, 25 April 2003. http://www.psychologytoday.com/articles/200304/vitamin-c-stress-buster

[28] Polidori, M.C., Mecocci, P. and Frei, B. (2001) Plasma Vitamin C Levels Are Decreased and Correlated with Brain Damage in Patients with Intracranial Hemorrhage or Head Trauma. Stroke, 32, 898-902. http://dx.doi.org/10.1161/01.STR.32.4.898

[29] Polidori, M.C., Praticó, D., Ingegni, T., Mariani, E., Spazzafumo, L. and Sindaco, P.D. (2005) Effects of Vitamin C and Aspirin in Ischemic Stroke-Related Lipid Peroxidation: Results of the AVASAS (Aspirin versus Ascorbic Acid plus Aspirin in Stroke) Study. BioFactors, 24, 265-274. http://dx.doi.org/10.1002/biof.5520240131

[30] Zweifler, R.M. (2003) Management of Acute Stroke. Southern Medical Journal, 96, 380-385. http://dx.doi.org/10.1097/01.SMJ.0000063467.75456.7A

\section{Abbreviations}

AA: ascorbic acid/vitamin C;

BID: in divided does, twice a day;

BCG: Bacillus Calmette-Guerin;

IV: intravenously;

SBC: superficial bladder carcinoma;

LUTS: lower urinary tract sypmtoms;

DCIP: dichlorophenol-indophenol;

GRAS: generally recognized as safe. 
Scientific Research Publishing (SCIRP) is one of the largest Open Access journal publishers. It is currently publishing more than 200 open access, online, peer-reviewed journals covering a wide range of academic disciplines. SCIRP serves the worldwide academic communities and contributes to the progress and application of science with its publication.

Other selected journals from SCIRP are listed as below. Submit your manuscript to us via either submit@scirp.org or Online Submission Portal.
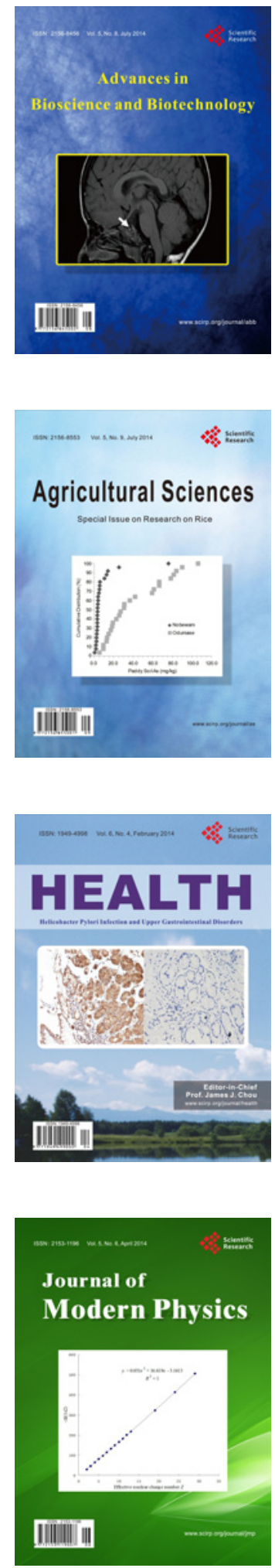
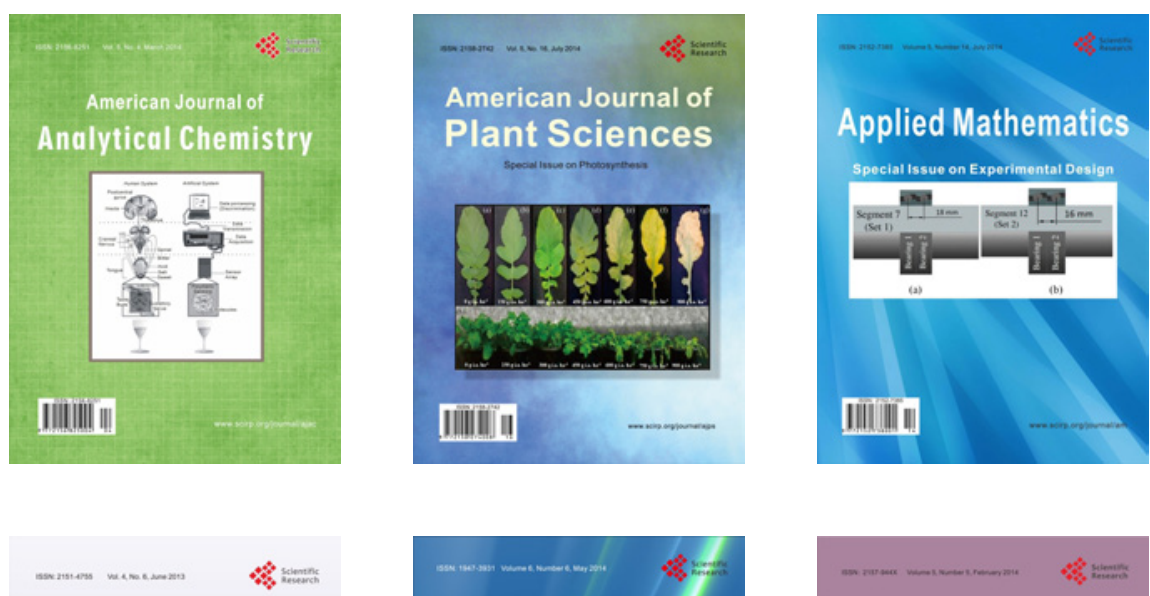

Creative Education
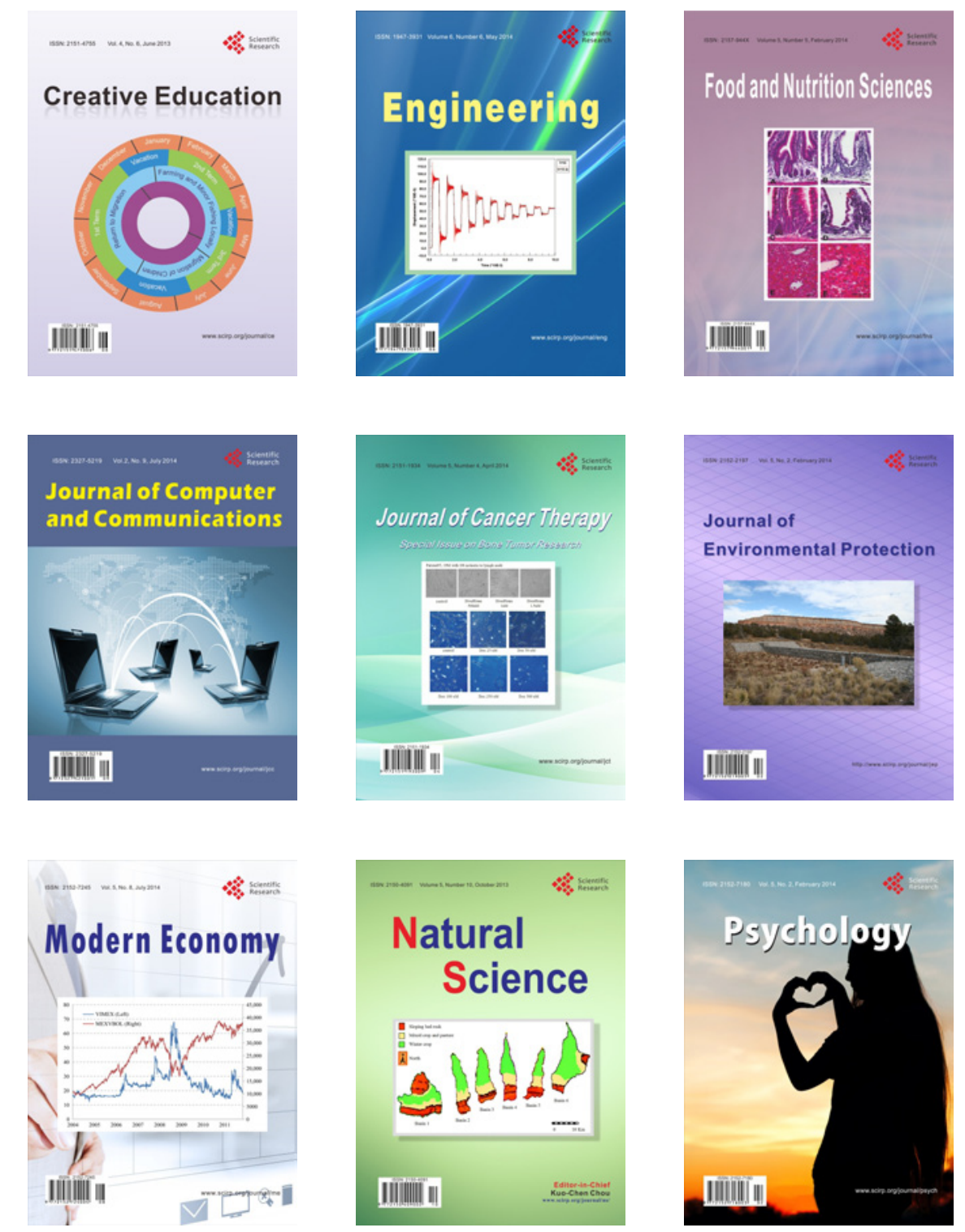